\title{
Peroral Treatment with Ciprofloxacin of Patients with Spinal Cord Lesion and Bacteriuria Caused by Multiply Resistant Bacteria
}

\author{
S. S. Pedersen, MD, ${ }^{1}$ S. Hørbov, $M D,{ }^{2}$ F. Biering-Sørensen, $M D, P h D,{ }^{2}$ \\ N. Høiby, MD, PhD ${ }^{1}$ \\ ${ }^{1}$ Statens Seruminstitut, Department of Clinical Microbiology at Rigshospitalet, \\ ${ }^{2}$ The Centre for Spinal Cord Injured, Department TH, Rigshospitalet, Copen- \\ hagen, Denmark.
}

\begin{abstract}
Summary
Eleven patients, median age 38 years, with spinal cord lesion (SCL) and urinary tract infection (UTI) caused by multiply resistant bacteria entered an open clinical trial of peroral ciprofloxacin $250 \mathrm{mg}$ b.i.d. for 6 days. P. aeruginosa was the most prevalent bacteria. Ciprofloxacin was clinically effective in all patients who had symptoms of UTI at entry. Bacterial eradication was achieved in 9 out of 11 patients immediately after treatment. At 4 weeks post-treatment 5 patients had relapse of bacteriuria with the initial micro-organism and only 2 had long term eradication. One patient had transient elevation of transaminases, but no other adverse reactions were noted. Pharmacokinetic analysis showed that ciprofloxacin was readily absorbed with a terminal half life of 2.5 hours and considerable nonrenal elimination. The urinary concentration of ciprofloxacin was high during the whole dosing interval. Oral treatment with ciprofloxacin is an alternative to parenteral antibiotics in $S C L$-patients with urinary tract infection caused by resistant bacteria.
\end{abstract}

Key words: Spinal cord lesions; Urinary tract infection; Ciprofloxacin.

Patients with spinal cord lesion (SCL) and neuropathic bladder often suffer from chronic and recurrent urinary tract infections (UTI). These infections are frequently caused by micro-organisms such as Pseudomonas aeruginosa which are resistant to commonly used antimicrobial agents (Geddes, 1979). Treatment of infections caused by these bacteria would often have to be given with drugs like the aminoglycosides which are only effective when given by the parenteral route. Treatment will therefore often necessitate admission to a hospital, it is 
therefore a major advance that peroral treatment of these infections has now become possible with the introduction of the fluoroquinolones such as ciprofloxacin (Boerema et al., 1985; Leigh et al., 1986; Ryan et al., 1987). Ciprofloxacin is a structural analogue of nalidixic acid and has very high in vitro activity against a wide variety of organisms including multiply resistant bacteria (Wise et al., 1983). The purpose of this investigation was therefore to evaluate the clinical and bacteriological efficacy of ciprofloxacin in SCL patients with urinary tract infection which were resistant to other peroral therapy.

SCL patients may have altered pharmacokinetics of drugs due to altered absorption and volume of distribution (Segal et al., 1985; Halstead et al., 1985) and the study therefore also evaluated the pharmacokinetics of ciprofloxacin in this group of patients.

\section{Patients and methods}

\section{Patients}

Eleven adult patients with SCL entered this open clinical trial. Ten had a spinal cord injury on traumatic basis and 1 had sequelae following spinal stenosis. Five patients (all males) were tetraplegic and 6 ( 5 male and 1 female) were paraplegic. Median age was 38 years (range $21-53$ years). The median time since diagnosis of SCL was 6 years (range 6 months-28 years). The mode of bladder emptying was suprapubic tapping (4), abdominal pressing (4) and intermittent catheterisation (3). All patients had normal upper urinary tracts as assessed by excretion urography. Patients were eligible for entry into the study if they had UTI with ciprofloxacin sensitive bacteria, which were resistant to usual oral drugs. Nine patients had chronic or recurrent bacteriuria and 2 had acute infection. The latter 2 infections were hospital-acquired during initial admission after acute spinal cord injuries. The study was approved by the regional ethics committee.

\section{Treatment}

The patients were given ciprofloxacin $250 \mathrm{mg}$ b.i.d. perorally for 6 days which were instituted only after bacteriological confirmation of UTI. The patients' usual medication for spasticity, pain and vitamin supplements were continued unchanged during the study.

\section{Diagnosis}

UTI was defined when urinary culture showed $\geqslant 10^{5}$ colony forming units $(\mathrm{CFU}) / \mathrm{ml}$ of urine. Urine was collected by interruption of mid-stream. If asymptomatic two positive cultures were required before initiation of therapy. The duration of UTI prior to treatment ranged from 8-400 days. After sampling the urine specimen was kept at $4^{\circ} \mathrm{C}$ until arrival at the bacteriological laboratory within 4 hours. Bacteria were grown on standard laboratory media and sensitivity to antimicrobials was determined with a table diffusion method (Neosensitabs ${ }^{\circledR}$, Rosco, Tåstrup, Denmark). 


\section{Assessment}

A physical examination was performed prior to entry and the clinical condition was observed daily during treatment. Urine samples were obtained during treatment at day 3 and 1 day, 1 week and 4 weeks after completion of treatment. Evaluaton of adverse reactions included a panel of laboratory tests for haematology, liver and kidney function, electrolytes and urinanalysis.

Clinical outcome was classified as: (1) resolution if all symptoms of UTI disappeared; (2) improvement if UTI symptoms had lessened; (3) failure if symptoms persisted or increased; (4) indeterminate response indicated that evaluation was not possible.

The bacteriological outcome was graded as: (1) eradication, when the number of causative organisms $<10^{3} \mathrm{CFU} / \mathrm{ml}$; (2) Persistent infection when the causative organism was present in numbers exceeding $10^{4} \mathrm{CFU} / \mathrm{ml}$; (3) Reinfection when the causative strains were eradicated but a new organism was present $>$ $10^{4} \mathrm{CFU} / \mathrm{ml}$; (4) Relapse was defined as occurring if the causative strains were eradicated during treatment, but recurred later. In cases of mixed infection with differential outcome between the bacteria the worst possible response with regard to the test drug was chosen.

\section{Pharmacokinetic analysis}

Urine and blood samples were collected on day 2 after the start of treatment. The patients were non-fasting. Blood was drawn with repeated venipunctures at time $0, \frac{1}{2}, 1,1 \frac{1}{2}, 2,3,6$ and 12 hours after intake of ciprofloxacin. Blood was allowed to clot at $4^{\circ} \mathrm{C}$ and serum was separated by centrifugation. Urine was collected $0-2,2-4,4-8$ and 8-12 hours after drug administration. The volume of each fraction was measured and a $10 \mathrm{ml}$ aliquot used for subsequent analysis. Urine and serum samples were stored at $-70^{\circ} \mathrm{C}$ until analysis. The concentration of ciprofloxacin was measurd with a microbiological assay using Escherichia coli as indicator strain. Reference standards of ciprofloxacin for serum was made in pooled human serum and for urine samples in phosphate buffered saline $(\mathrm{pH}$ $7 \cdot 2$ ). All samples were tested in duplicate. The lower detection limit of the assay was $0 \cdot 13 \mathrm{mg} / \mathrm{l}$.

The area under the serum concentration-time curve from 0-12 hours (AUC) was calculated by the trapezoidal rule. The absorption fraction of the drug in SCL patients is unknown and the apparent serum clearance of it was calculated from the equation: $\mathrm{CL}_{\mathrm{app}}=$ dose/AUC (at steady state). Renal clearance was calculated as $\mathrm{CL}_{\text {ren }}=\mathrm{A}_{\mathrm{e}} / \mathrm{AUC}$, where $\mathrm{A}_{\mathrm{e}}$ is the total amount of drug excreted in the urine during the dosing interval. Non-renal clearance $\mathrm{CL}_{\text {non-ren }}$ was equal to $\mathrm{CL}_{\text {app }}-\mathrm{CL}_{\mathrm{ren}}$. All clearances were given per $\mathrm{kg}$ body weight. Mean serum concentration $\left(\mathrm{C}_{\mathrm{s}}\right)$ was calculated as $\mathrm{AUC} / 12 \mathrm{~h}$. The elimination rate constant $\left(\mathrm{k}_{\mathrm{e}}\right)$ was calculated by the equation $\mathrm{k}_{\mathrm{e}}=2.303 \times$ slope of the logarithmic plot of the serum concentration-time curve for each patient and the slope was obtained by linear regression analysis of the elimination phase. The terminal half-life was found as $T_{1 / 2 \beta}=\ln 2 / k_{\mathrm{e}}$. 
Table I Number of patients with pathogenic bacteria isolated from the urine before treatment with ciprofloxacin, $\mathrm{n}=11$

\begin{tabular}{ll}
\hline Pseudomonas aeruginosa & 7 \\
Pseudomonas, other & 1 \\
Escherichia coli & 2 \\
Proteus rettgeri & 2 \\
Proteus mirabilis & 1 \\
Streptococcus faecalis & 2 \\
Streptococcus agalactiae & 1 \\
Klebsiella pneumoniae & 1 \\
Acinetobacter calcoaceticus & 1 \\
Providencia stuartii & 1 \\
\hline
\end{tabular}

Table II Bacteriological efficacy of ciprofloxacin $250 \mathrm{mg}$ B.D. for 6 days in patients with spinal cord lesion and urinary tract infection

\begin{tabular}{lcccc}
\hline & $\begin{array}{c}\text { During treatment } \\
\text { Day 1 }\end{array}$ & Day 3 & $\begin{array}{c}\text { Post-treatment } \\
\text { Week 1 }\end{array}$ & Week 4 \\
\hline Eradication & 9 & 9 & 4 & 2 \\
Persistence & 0 & 1 & 0 & 0 \\
Re-infection & 0 & 0 & 2 & 3 \\
Relapse & 0 & 1 & 4 & 5 \\
Not evaluable & 2 & 0 & 1 & 1 \\
\hline
\end{tabular}

\section{Results}

\section{Clinical and bacteriological efficacy}

Five patients did not experience symptoms of UTI before treatment and their clinical response was therefore indeterminate. Six patients had symptoms of UTI and the symptoms resolved completely at the end of treatment in 4 patients and improved in 2 .

One patient experienced an increase in transaminases which normalised after treatment was completed. No other adverse reactions were observed and other laboratory parameters remained within normal ranges.

Table I shows the bacteriological findings in the urine prior to start on the study drug. $P$. aeruginosa was the most prevalent bacteria. Six patients had an infection caused by a single species, whereas 5 had mixed infection with 2-4 different bacterial species.

Table II shows the bacteriological outcome during treatment, 1 day, 1 week and 4 weeks after completion of treatment. Inadequate sampling meant that some patients were not evaluated continuously. Ciprofloxacin was highly effective in sterilising the urine during and immediately after treatment leading to a short term outcome of bacterial eradication in 9 out of 11 patients. Long term eradication was however only achieved in 2 patients at 4 weeks, whereas 5 relapsed with significant bacteriuria of the initially causative micro-organism and 3 patients had acquired new micro-organisms.

$P$. aeruginosa could be eradicated during treatment in all patients infected with this bacteria, but was only eradicated in 1 patient at 4 weeks. Four patients 
Table III Steady state pharmacokinetic parameters for oral ciprofloxacin, $250 \mathrm{mg}$ in 11 patients with spinal cord lesions

\begin{tabular}{lccccccc}
\hline & $\mathrm{C}_{\max }, \mathrm{mg} / \mathrm{l}$ & $\mathrm{T}_{\max }, \mathrm{h}$ & $\mathrm{C}_{\mathrm{s}}, \mathrm{mg} / \mathrm{l}$ & $\mathrm{AUC}, \mathrm{mg} / \mathrm{l} / \mathrm{h}$ & $\mathrm{K}_{\mathrm{e}}, \mathrm{h}^{1}$ & $\mathrm{~T}_{1 / 2} \beta, \mathrm{h}$ & $\mathrm{CL}_{\mathrm{app}}, \mathrm{ml} / \mathrm{min} / \mathrm{kg}$ \\
\hline Mean & 1.0 & 1.4 & 0.26 & $3 \cdot 2$ & 0.288 & 2.5 & $24 \cdot 2$ \\
SD & 0.39 & 0.4 & 0.10 & 1.2 & 0.070 & 0.6 & $15 \cdot 7$
\end{tabular}

$\mathrm{C}_{\mathrm{max}}$ : maximal concentration of drug in serum, $\mathrm{C}_{\mathrm{s}}$ : mean serum concentration, AUC: area under concentration curve from $0-12$ hours; $\mathrm{K}_{\mathrm{e}}$ : elimination constant, $\mathrm{T}_{1 ; 2 \beta}$ : elimination half-life, $\mathrm{CL}_{\text {app }}$ : apparent total clearance.

Table IV Excretion and urinary recovery after $250 \mathrm{mg}$ ciprofloxacin in 5 patients with spinal cord lesions

\begin{tabular}{|c|c|c|c|c|c|c|c|c|}
\hline & \multicolumn{8}{|c|}{ Concentration $(\mathrm{mg} / \mathrm{l})$ in collection period } \\
\hline & $0-2$ & $2-4$ & $4-8$ & $8-12$ & $\mathrm{mg}$ & $\mathrm{ml} / \mathrm{min} / \mathrm{kg}$ & $\mathrm{ml} / \mathrm{min} / \mathrm{kg}$ & $\begin{array}{c}\text { Recovery } \\
\%\end{array}$ \\
\hline Mean & 67 & 79 & 35 & 23 & 58 & $4 \cdot 5$ & $15 \cdot 8$ & 23 \\
\hline SD & 38 & 64 & 25 & 23 & 26 & 1.9 & $5 \cdot 4$ & 10 \\
\hline
\end{tabular}

$\mathrm{A}_{\mathrm{e}}$ : amount of drug excreted 0-12 hours, $\mathrm{CL}_{\text {ren }}:$ renal clearance, $\mathrm{CL}_{\text {non-ren }}:$ non-renal clerance.

with $P$. aeruginosa had relapsed at follow-up after 4 weeks. These patients had been paralysed from 10-28 years having a chronic infection. Two patients with acute spinal cord injury ( $\frac{1}{2}-2 \frac{1}{2}$ months) and hospital acquired $P$. aeruginosa had bacteriological eradication of acute UTI, but had become reinfected with other micro-organisms at 4 weeks.

Except for one strain of Pseudomonas which were resistant to ciprofloxacin at day 7 all the strains isolated during this study were sensitive to ciprofloxacin.

\section{Pharmacokinetic analysis}

Pharmacokinetic parameters are shown in Table III. Ciprofloxacin was readily absorbed and reached peak levels in serum 1.4 hours after intake. The mean elimination half-life was 2.5 hours, ranging from 1.6-3.6 hours. Table IV shows the concentration of ciprofloxacin in urine in 5 patients. The concentration was high during the whole dosing interval. However, in some patients concentration may fall to low levels at the end of the interval. Urinary recovery of biologically active substances were $23 \%$ in the 12 -hour collection period. Nearly $\frac{3}{4}$ of the dose were cleared from the plasma by non-renal routes.

\section{Discussion}

Patients with a neuropathic bladder are prone to acquire urinary tract infection mainly because of insufficient emptying of the bladder. Untreated the infection often leads to the formation of urinary calculi, ascending infection and renal failure which has been associated with a poor long term prognosis in SCL patients (Guttmann, 1976; Ruutu and Lehtonen, 1984). Urinary tract infections continue to cause significant morbidity after SCL (Cardenas and Mayo, 1987). The infection is commonly caused by opportunistic pathogens such as P. aeruginosa and other species which rarely cause overt clinical diseases in other patients. From a bacteriological point of view these bacteria (Table I) are often 
termed multiply resistant as they are not amenable to treatment with peroral drugs because they are not susceptible to these.

The quinolones, like ciprofloxacin, have been found to be very effective in the treatment of various infections caused by bacteria, which are usually difficult to treat (Ball, 1986). Although the number of patients in our study was relatively small it showed that ciprofloxacin was very effective in SCL patients in achieving short term urinary sterilisation which were associated with relief of symptoms and without serious side-effects. Similar results have been obtained by other invstigators studying complicated urinary tract infection (Fass, 1987; Gasser et al., 1987a).

However, evaluation at 4 weeks after treatment showed a high rate of relapse, which is in accordance with other studies involving patients with neuropathic bladder (von Poppel, 1986; Fass, 1987). Re-infection or relapse of infection is hardly surprising with a treatment course lasting only 6 days and permanent eradication of urinary infections caused byu $P$ aeruginosa in patients with bladder dysfunction is difficult to achieve (Geddes, 1979). However, the oral availability of ciprofloxacin makes possible longer duration of therapy, e.g. 6 weeks, which may reduce the relapse rate.

Ciprofloxacin was well tolerated and side-effects like gastrointestinal disturbances and dizziness were not recorded. Laboratory parameters did not change, except in 1 patient with transient elevation of hepatic enzymes.

Tetraplegic patients have been shown to have a reduction in the rate of absorption of passively absorbed drugs (Halstead et al., 1985), but we found that ciprofloxacin was well absorbed reaching maximal serum concentration $\left(\mathrm{C}_{\max }\right)$ about $1 \frac{1}{2}$ hours after intake ( $\mathrm{T}_{\max }$ ) which is comparable to the data of Borner et al. (1986), who investigated the pharmacokinetics in non-fasting healthy volunteers. Ciprofloxacin is rapidly excreted into the urine and high concentrations were achieved even within 2 hours of drug intake. However, the half-life is considerably shorter in our patients (Table III) than in other studies where it was found to range between 3 and 5 hours (Wingender et al., 1984; Borner et al., 1986). High concentrations of ciprofloxacin were achieved in the urine and in most of the dosing interval by far exceeding the minimal concentrations necessary to inhibit growth of urinary tract pathogens (Wise et al., 1983; Fass, 1983). In a few of our patients the concentration towards the end of the interval was rather low and taking into account the relatively short half-life a twice daily schedule should be recommended for this dosage of ciprofloxacin. A higher dose once a day might improve the urinary concentrations and making administration more easy. Extrarenal routes are important for the elimination of ciprofloxacin (Wingender et al., 1984) and is confirmed in this study to account for nearly $\frac{3}{4}$ of the total body clearance. Hence, ciprofloxacin may also be used in patients with impaired renal function (Gasser et al., 1987b), although reduction in dosage may be necessary.

An effective drug, which can be taken by outpatients is likely to be of significant physical and social benefit to patients suffering from chronic or recurrent infection with multiply resistant urinary pathogens and oral therapy with ciprofloxacin may represent a promising advance in the management of SCL patients who would otherwise often be admitted to hospital for parenteral antibiotic treatment. 
An effective and orally absorbed drug may also be useful for prophylactic treatment of SCL patients and low dose nitrofurantoin therapy has been shown to be effective in preventing UTI in these patients (Merritt et al., 1982; Linden and Joiner, 1984). However, the antibacterial spectrum of nitrofurantoin would not cover many of the pathogens isolated in this study and we are currently studying the effectiveness of ciprofloxacin as preventive antibacterial therapy against UTI in SCL-patients.

\section{Acknowledgement}

Bayer Sweden AB supplied the ciprofloxacin tablets.

\section{References}

BALl AP 1986 Overview of clinical experience with ciprofloxacin. European fournal of Clinical Microbiology 5:214-219.

Boerema J, Boll B, MuYtgens M, et al. 1985 Efficacy and safety of ciprofloxacin (Bay o 9867) in treatment of patients with complicated urinary tract infections. Fournal of Antimicrobial Chemotherapy 16:211-217.

BORNER K, HÖFFKEN G, LODE H, et al. 1986 Pharmacokinetics of ciprofloxacin in healthy volunteers after oral and intravenous administration. European fournal of Clinical Microbiology 5:179-186.

CARdenas DD, Mayo ME 1987 Bacteriuria with fever after spinal cord injury, Archives of Physical Medicine and Rehabilitation 68:291-293.

FASS RJ 1983 In vitro activity of ciprofloxacin (Bay o 9867). Antimicrobial Agents and Chemotherapy 24:568-574.

FASS RJ 1987 Efficacy and safety of oral ciprofloxacin for treatment of serious urinary tract infections. Antimicrobial Agents and Chemotherapy 31:148-150.

Gasser TC, Graversen PH, MAdSEN PO 1987a Treatment of complicated urinary tract infections with ciprofloxacin. The American fournal of Medicine 82:278-283, Supplement 4A.

GASSER TC, EBERT SC, GRAVERSEN PH, et al. 1987b Ciprofloxacin pharmacokinetics in patients with normal and impaired renal function. Antimicrobial Agents and Chemotherapy 31:709-712.

GEDDES AM 1979 Other infections. In: Pseudomonas aeruginosa, the organism, diseases it causes and their treatment. SABath LD (Ed) Hans Huber Publishers, Bern, pp. 89-100.

GutTMANN L 1976 Spinal Cord Injuries, comprehensive management and research. Blackwell Scientific Publications, Oxford.

Halstead LS, Feldman S, Claus-Walker J, et al. 1985 Drug absorption in spinal cord injury. Archives of Physical Medicine and Rehabilitation 66:298-301.

Leigh PA, Emmanuel FXS, Petch VJ 1986 Ciprofloxacin therapy in complicated urinary tract infections caused by Pseudomonas aeruginosa and other resistant bacteria. Fournal of Antimicrobial Chemotherapy 18:117-121, Supplement D.

LINDAN R, JOINER E 1984 A prospective study of the efficacy of low dose nitrofurantoin in preventing urinary tract infections in spinal cord injury patients with comments on the role of Pseudomonads. Paraplegia 22:61-65.

MERRITT JL, ERICKSON RP, OPITZ JL 1982 Bacteriuria during follow-up in patients with spinal cord injury: II. Efficacy of antimicrobial suppressants. Archives of Physical Medicine and Rehabilitation 62:413-415.

RUUTU M, LEHTONEN T 1984 Urinary tract complications in spinal cord injury patients. Annales Chirurgiae et Gynaecologiae 73:325-330.

RYAN JL, BERENSON CS, GRECO TP, et al. 1987 Oral ciprofloxacin in resistant urinary tract infections. The American fournal of Medicine 82:303-306, Supplement A.

SEGAL JL, Gray DR, Gordon SK, et al., 1985 Gentamicin disposition kinetics in humans with spinal cord injury. Paraplegia 23:47-55.

Van Poppel H, Wegge M, Dammekens H, Chysky V 1986 Ciprofloxacin in the treatment of urinary tract infection in patients with multiple sclerosis. European fournal of Clinical Microbiology 5:251-253.

Wingender W, Graefe K-H, GaU W et al. 1984 Pharmacokinetics of ciprofloxacin after oral and intravenous administration in healthy volunteers. European fournal of Clinical Microbiology 3:355-359.

Wise R, ANDREwS JM, EDWARDS LJ 1983 In vitro activity of Bay o 9867, a new quinolone derivative, compared with those of other antimicrobial agents. Antimicrobial Agents and Chemotherapy 23:559-564. 